\title{
Admissions for Pediatric Diarrheal Illness in a Southern Indian Hospital Peak during the Rainiest Month of the Year
}

\author{
Vijay Anand ${ }^{1}$, Peter Milano ${ }^{2 *}$, John R Allegra ${ }^{3}$ and Kuruvilla Thomas ${ }^{1}$
}

${ }^{1}$ Sundaram Medical Foundation, Dr. Rangarajan Memorial Hospital, $4^{\text {th }}$ Avenue, Shanthi Colony, Annanagar, Chennai 600040 , India

${ }^{2}$ Department of Emergency Medicine, Los Angeles County, University of Southern California, USA

${ }^{3}$ Morristown Medical Center Residency in Emergency Medicine, USA

\begin{abstract}
Objectives: To test our hypothesis that admissions for diarrheal illness to a southern Indian hospital would be highest in the month with the most rainfall.

Methods: Design: Retrospective cohort. Setting: Community hospital in Chennai, southern India. Population: All pediatric patients (less than 16 years of age) admitted to the hospital from January 1, 2001 to December 31, 2004 Protocol: We selected diagnoses associated with acute diarrhea from all admitted pediatric patients, and used Chi square and the Student's t-tests to test for statistical significance, with alpha set at 0.05.

Results: Of the 3,660 pediatric admissions, there were 740 admissions for diarrheal illness. Of those 740 , the average age was 1.8 years and $47 \%$ were female. There was non-uniformity by month for diarrheal illness admissions using Chi square $(\mathrm{p}<0.001)$. The month with the greatest rainfall, November, had the highest admissions for diarrheal illness: 2.3 times more $(95 \% \mathrm{Cl} 2.0-2.6, p<0.001)$ than the mean for the other 11 months.

Conclusions: The number of pediatric admissions for diarrheal illness is highest in the rainiest month. We speculate that this may be due to contamination of the water supply and recommend that an educational program targeting parents be instituted before the rainy season.
\end{abstract}

Keywords: Diarrheal illness; Pediatric admissions; Waterborne; Rainfall

\section{Introduction}

The mortality rate in India in 2004 was $6 \%$ in infants under 12 months of age, and $8 \%$ in children under 5 years of age [1]. This was more than 10 times higher than in the United States that year [1]. India is a country that depends heavily on prevention for the improvement of health, as total health expenditures in 2002 were $\$ 96$ per capita. Because diarrheal illness is a leading cause of morbidity and mortality among the pediatric populations of developing countries [2,3], it is an important disease. Surveillance of this illness may be useful in identifying opportunities for reducing morbidity and mortality.

Many causative enteropathogens for diarrheal illness are waterborne [4]. We hypothesized that, due to water contamination during the rainy season, the number of pediatric admissions to the hospital for diarrheal illness would be greatest during the month with the most rainfall. If a correlation exists, it may be useful in planning educational programs related to sanitation for the period of time during which they can have the greatest impact on reducing diarrheal illness.

\section{Methods}

\section{Design}

Retrospective cohort of pediatric admissions to the hospital. Population: All pediatric patients (less than 16 years of age) admitted to the hospital from January 1, 2001 to December 31, 2004. Setting: Community teaching hospital in Chennai, southern India. Protocol: We examined all diagnoses of admitted pediatric patients and selected those associated with acute diarrhea. We then analyzed these data for the four year period by month in a Microsoft ${ }^{\oplus}$ Excel $^{\oplus}$ spreadsheet. We used Chi square and the two-tailed Student's t-test (SPSS Version 7.5) to determine statistical significance with alpha set at 0.05 . The institutional review board at the study site approved this project.

\section{Results}

Of the 3,660 pediatric admissions during the study period, there were 740 admissions for diarrheal illness. Figure 1 gives the breakdown by age. Of those 740 , the average age was 1.8 years, $47 \%$ were female, $36 \%$ were in their first year of life, and $30 \%$ were in their second year.

Figure 2 shows the monthly admissions for pediatric diarrheal illness for the four year period, and average rainfall by month. Nonuniformity by month for admissions for diarrheal illness was found using the Chi square test $(p<0.001)$. The month with the greatest rainfall, November, had the highest number of admissions for diarrheal illness: 2.3 times more admissions $(95 \%$ CI 2.0-2.6, $<<0.001)$ than the mean for the other 11 months of the year.

\section{Discussion}

In agreement with our hypothesis, we found that admissions for diarrheal illness were highest in the month with the most rainfall. Other investigators have found a similar correlation in Nicaragua, the Pacific Islands, the Philippines, and Thailand [5-8]. More specifically, heavy rainfall has been implicated in increased transmission of Giardiasis in the adult population of Dakshina Kannadad district of

*Corresponding author: Peter Milano, Department of Emergency Medicine, Los Angeles County, University of Southern California, USA, Tel: 818 519-6746; E-mail: peter.milano@gmail.com

Received September 26, 2013; Accepted October 15, 2013; Published October 20, 2013

Citation: Anand V, Milano P, Allegra JR, Thomas K (2013) Admissions for Pediatric Diarrheal Illness in a Southern Indian Hospital Peak during the Rainiest Month of the Year. Trop Med Surg 1: 150. doi:10.4172/2329-9088.1000150

Copyright: $\odot 2013$ Anand V, et al. This is an open-access article distributed unde the terms of the Creative Commons Attribution License, which permits unrestricted use, distribution, and reproduction in any medium, provided the original author and source are credited. 


\section{Percent of Diarrhea Admissions versus Age}

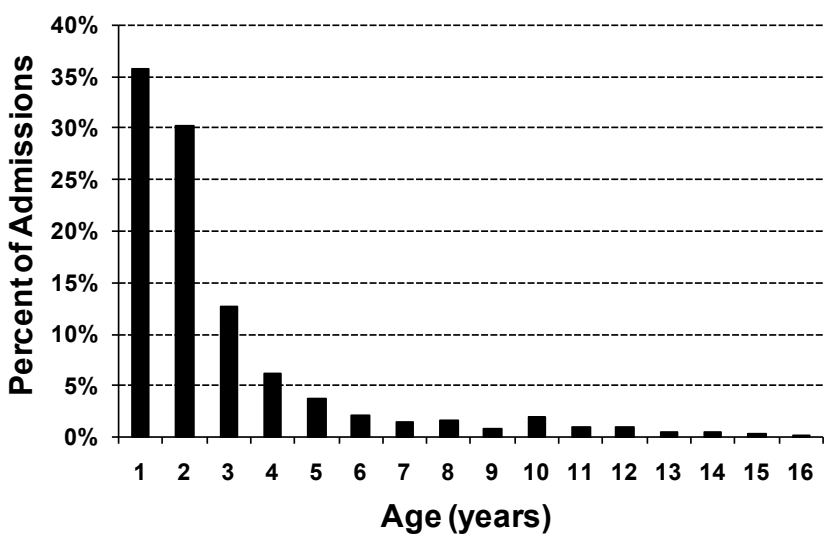

Figure 1: Percent of Diarrhea Admissions versus.

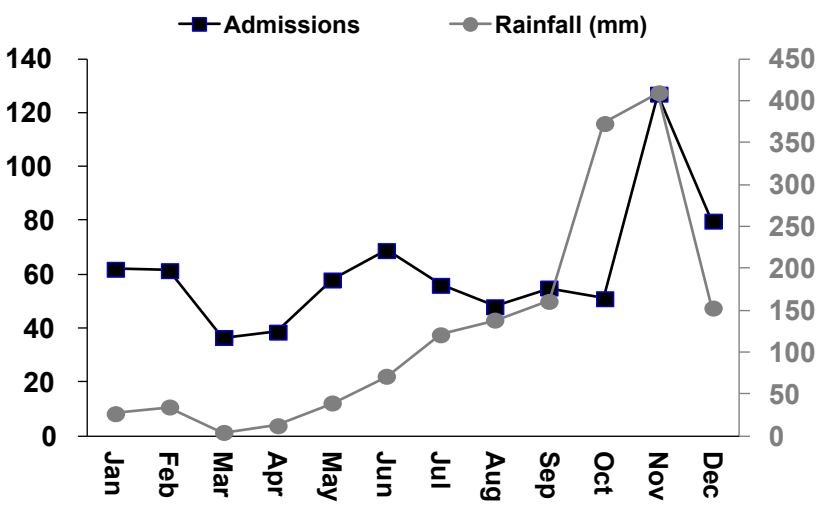

Figure 2: Admission for pediatric diarrheal illness and average rainfall by month.

south India(9), cholera in Indonesia $[9,10]$ and the Philippines, and Shigella in Thailand $[7,11]$.

Other investigators have not been able to correlate rainfall and diarrheal illness. No correlation was found in studies in southern Brazil, Varanasi, India, or Malaysia $[9,12,13]$. In fact, the human rotavirus diarrheal cases in Kuwait and Dibrugarh, India decreased during the rainy season $[14,15]$. This may be due to the fact that rotavirus is transmitted mainly through means other than contaminated water [16]. The fact that some investigators found no increase in the rainy season may be due to differences in water supplies, surveillance techniques and severity of illness. In particular we analyzed only those with the greatest severity of illness, admitted patients.

We speculate that the chief reason for our findings is the water contamination caused by flooding. This notion has been supported in Gambia, where water is obtained predominantly from surface wells [17]. It was found that, although the water contained fecal contaminants throughout the year, the level of contamination increased by up to onehundred times at the start of the rainy season from additional fecal matter washing into the wells [17]. In developing counties, however, water contamination is a problem often complicated by more than just flooding. For instance, in Rwanda, it has been found that the major sources of contamination of the water supply included the use of unclean containers to transport and store water in addition to rainfall contamination [18].

The increase in diarrheal illness we found during the month with the most rainfall may have complex additional causes, including cultural and socioeconomic factors. In Thailand, for example, it has been found that both dysentery and diarrhea in children were associated with the occupational behavior of people in each season, and ambient temperature, in addition to rainfall [8]. In Bangladesh, Rowland [17] found that diarrheal illness shows a significant rainy season peak, but notes that this period is also the main farming season. Rowland suggests that during this period mothers working on farms have less time for breastfeeding, leading perhaps to poorer nutritional status for children and an increased intake of contaminated water [17].

In Lima, Peru, it has been reported that diarrheal pathogens such as Campylobacter jejuni, Escherichia coli, Shigella, rotavirus and Cryptosporidum appeared to be transmitted to infants not only through feces and contaminated water and food, but also by direct person-toperson contact [19]. It is also possible that the peak in diarrheal illness that we found is caused at least in part by families spending more time in their homes together during periods of heavy rainfall.

The rainy season begins in October in Chennai, while the sharp increase in admissions for diarrheal illness we have found does not begin until November. We suspect that this delay may be due in part to incubation periods for some waterborne pathogens may take 1 to 4 weeks to incubate [4]. We speculate that this may also be due to delays in the time floodwaters take to contaminate the water supply.

Management of the burden of this disease in children should include attention to prevention. In Bangladesh, it has been found that low educational status is a risk factor associated with infection with cholera [20]. Parental educational programs focused on the period before the rainy season will likely yield the highest reduction in admissions for pediatric diarrheal illness. Most of the patients in our series were under five years of age; therefore, an intervention should be directed at infants and children before they enter school. It may be possible to have all pediatricians in the service area of the hospital educate the caregivers about the higher risk of serious diarrheal illness during the rainy season through discussion with the caregivers, or factsheets for them to take home. This may be most expeditiously done during routine childhood immunizations.

\section{Limitations}

The use of the admissions database of one hospital leads to some limitations to our results. Without a multi-institutional database, we may have selected for a divergent subset of the population of Chennai. In addition, only the sickest patients are admitted and recorded in the database used for this study. We did not, for example, include those seen and discharged from the emergency department.

\section{Conclusions}

The number of pediatric admissions to the hospital for diarrheal illness is highest in November, the month with the most rainfall. We speculate that this is due to contamination of the water supply, and recommend an educational program targeting parents, particularly those with children under the age of five, be instituted before the rainy season in an effort to reduce admissions for diarrheal illness.

\section{References}

1. World Population Prospects: The 2004 Revision. 2005. New York, United Nations. 
Citation: Anand V, Milano P, Allegra JR, Thomas K (2013) Admissions for Pediatric Diarrheal Illness in a Southern Indian Hospital Peak during the Rainiest Month of the Year. Trop Med Surg 1: 150. doi:10.4172/2329-9088.1000150

2. Saidi SM, lijima Y, Sang WK, Mwangudza AK, Oundo JO, et al. (1997) Epidemiological study on infectious diarrheal diseases in children in a coastal rural area of Kenya. Microbiol Immunol 41: 773-778.

3. Sankaranarayanan VS, Srinivas S (2003) Management of acute diarrhoea in children. J Indian Med Assoc 101: 660-663.

4. Feigin R, Cherry J, Demmler G, Kaplan S (2004) Textbook of Pediatric Infectious Diseases. Philadelphia: W.B. Saunders Company.

5. Sandiford P, Gorter AC, Smith GD, Pauw JP (1989) Determinants of drinking water quality in rural Nicaragua. Epidemiol Infect 102: 429-438.

6. Singh RB, Hales S, de Wet N, Raj R, Hearnden M, et al. (2001) The influence of climate variation and change on diarrheal disease in the Pacific Islands. Environ Health Perspect 109: 155-159.

7. Adkins HJ, Escamilla J, Santiago LT, Rañoa C, Echeverria P, et al. (1987) Twoyear survey of etiologic agents of diarrheal disease at San Lazaro Hospital, Manila, Republic of the Philippines. J Clin Microbiol 25: 1143-1147.

8. Sutra S, Srisontrisuk S, Panpurk W, Sutra P, Chirawatkul A, et al. (1990) The pattern of diarrhea in children in Khon Kaen, northeastern Thailand: I. The incidence and seasonal variation of diarrhea. Southeast Asian J Trop Med Public Health 21: 586-593.

9. Shenoy S, Urs S, Prabhu G, Mathew B, Antony G, et al. (1998) Giardiasis in the adult population of Dakshina Kannada district of south India. Trop Doct 28 : $40-42$

10. Simanjuntak CH, Larasati W, Arjoso S, Putri M, Lesmana M, et al. (2001) Cholera in Indonesia in 1993-1999. Am J Trop Med Hyg 65: 788-797.

11. Echeverria $P$, Pitarangsi $C$, Eampokalap $B$, Vibulbandhitkit $S$, Boonthai $P$, et al. (1983) A longitudinal study of the prevalence of bacterial enteric pathogens among adults with diarrhea in Bangkok, Thailand. Diagn Microbiol Infect Dis 1: $193-204$.

12. Victora CG, Vaughan JP, Barros FC (1985) The seasonality of infant deaths due to diarrheal and respiratory diseases in southern Brazil, 1974-1978. Bull Pan Am Health Organ 19: 29-39.

13. Yap KL, Sabil D, Muthu PA (1983) Human rotavirus infection in Malaysia. III. A one year survey on the prevalence of rotavirus enteritis in children. Southeast Asian J Trop Med Public Health 14: 467-469.

14. Sethi SK, Al-Nakib W, Khuffash FA, Majeed HA (1984) Acute diarrhoea and rotavirus infections in young children in Kuwait. Ann Trop Paediatr 4: 117-121.

15. Phukan AC, Patgiri DK, Mahanta J (2003) Rotavirus associated acute diarrhoea in hospitalized children in Dibrugarh, north-east India. Indian J Pathol Microbiol 46: $274-278$

16. Mandel G, Bennett J, Dolin R (2005) Principles and Practice of Infectious Disease. Churchill Livingstone.

17. Rowland MG (1986) The Gambia and Bangladesh: the seasons and diarrhoea. Dialogue Diarrhoea : 3.

18. Gasana J, Morin J, Ndikuyeze A, Kamoso P (2002) Impact of water supply and sanitation on diarrheal morbidity among young children in the socioeconomic and cultural context of Rwanda (Africa). Environ Res 90: 76-88.

19. Black RE, Lopez de Romaña G, Brown KH, Bravo N, Bazalar OG, et al. (1989) Incidence and etiology of infantile diarrhea and major routes of transmission in Huascar, Peru. Am J Epidemiol 129: 785-799.

20. Ali M, Emch M, Donnay JP, Yunus M, Sack RB (2002) The spatial epidemiology of cholera in an endemic area of Bangladesh. Soc Sci Med 55: 1015-1024. 